\title{
Perceived Packaging, Perceived Value, Perceived Quality dan Purchase Intention pada Tenun Kubang di Kabupaten Lima Puluh Kota
}

\section{Perceived Packaging, Perceived Value, Perceived Quality and Purchase Intention on Kubang Weaving in Lima Puluh Kota Regency}

\author{
Ratni Prima Lita ${ }^{1)},{\text { Meuthia } \text { Meuthia }^{2)} \text {, Henmaidi Alfian }}^{3)}$, Debi Shintya Dewi ${ }^{4)}$ \\ ${ }^{1,2,4)}$ Fakultas Ekonomi, Universitas Andalas, Kota Padang \\ ${ }^{3)}$ Fakultas Teknik, Universitas Andalas, Kota Padang \\ e-mail korespondensi: ratniprimalita@eb.unand.ac.id
}

\begin{tabular}{|l|}
\hline Info Artikel \\
\hline Riwayat Artikel : \\
Diterima: 15 Juni 2020 \\
Disetujui: 22 Juli 2020 \\
Dipublikasikan: Januari 2021 \\
\hline Nomor DOI \\
10.33059/jseb.v12i1.2418 \\
Cara Mensitasi : \\
Lita, R.P., Meuthia, M., \\
Alfian, H., \& Dewi, D. S. \\
(2021). Perceived packaging, \\
perceived value, perceived \\
quality dan purchase intention \\
pada tenun kubang di \\
Kabupaten Lima Puluh Kota. \\
Jurnal Samudra Ekonomi dan \\
Bisnis, 12(1), 46-61. doi: \\
10.33059/ jseb.v12i1.2418.
\end{tabular}

Abstrak

Salah satu produk kreatif yang menjadi industri unggulan Propinsi Sumatera Barat khususnya daerah Limapuluh Kota adalah Tenun Kubang. Salah satu usaha tenun Kubang terkenal H. Ridwan BY. adalah Tujuan penelitian ini untuk menganalisis perceived packaging, perceived value, perceived quality dan purchase intention pada produk tenun Kubang tersebut. Penelitian deskriptif ini menggunakan sampel 95 responden. Unit analisis adalah konsumen yang pernah maupun belum pernah bertransaksi dengan tenun Kubang H. Ridwan BY, namun familiar atau tahu mengenai tenun Kubang tersebut. Hasil penelitian melalui aplikasi distribusi frekuensi memberikan beberapa implikasi dan rekomendasi kepada pihak usaha tenun Kubang H. Ridwan BY yaitu harus meningkatkan perceived packaging, perceived value, dan perceived quality. Hal ini bertujuan agar purchase intention konsumen dan calon konsumen bisa meningkat.

Kata Kunci: Perceived Packaging, Perceived Value, Perceived Quality, Purchase Intention.

\section{Article Info}

\section{Article History :}

Received: 15 June 2020

Accepted: 22 July 2020

Published: January 2021

\section{DOI Number :}

$10.33059 /$ jseb.v12i1 2418

How to cite :

Lita, R.P., Meuthia, M., Alfian, H., \& Dewi, D. S. (2021). Perceived packaging, perceived value, perceived quality dan purchase intention pada tenun kubang di Kabupaten Lima Puluh Kota. Jurnal Samudra Ekonomi dan Bisnis, 12(1), 46-61. doi: 10.33059/ jseb.v12i1.2418.

\section{Abstract}

One of the creative products that become superior industry in West Sumatra Province, especially in the Limapuluh Kota area, is Weaving Kubang. The purpose of this study was to analyze the perceived packaging, perceived value, perceived quality and purchase intention of the Kubang woven products. One of the famous Kubang weaving businesses is H. Ridwan BY. This descriptive study used a sample of 95 respondents. The unit of analysis is consumers who have or have never transacted with H. Ridwan BY's Kubang weaving, but are familiar or know about the Kubang weaving. The results of the research through the application of frequency distribution provide several implications and recommendations to the $H$. Ridwan BY's Kubang weaving business, namely to increase perceived packaging, perceived value, and perceived quality. It is intended that the purchase intention of consumers and potential consumers can increase.

Keywords: Perceived Packaging, Perceived Value, Perceived Quality, Purchase Intention. 


\section{PENDAHULUAN}

Industri kerajinan memberi kontribusi pada peningkatan nilai tambah, penyerapan tenaga kerja, serta pengembangan pasar dengan melakukan ekspor. Hal ini bisa dilakukan oleh industri kerajinan dengan memanfaatkan kemampuan sumber daya manusia untuk menghasilkan produk-produk kreatif dan inovatif, sehingga meningkatkan daya saing di pasar global (Lita et al., 2018).

Menurut argument dari Meirejeki et al. (2017), industri kerajinan tenun adalah industri unggulan dengan berbagai produk dan corak yang banyak digemari masyarakat lokal maupun luar daerah. Tenun adalah seni budaya yang berasal dari keterampilan, dan diturunkan dari generasi ke generasi (Barus et al., 2015). Kerajinan tenun merupakan teknik pembuatan sebuah kain dengan menggunakan bahan baku serat atau benang. Banyak potensi ekonomi yang dapat dikembangkan dengan tenun, dikarenakan desain motifnya dapat dikembangkan untuk menciptakan industri yang berkelanjutan (Barus et al., 2015). Menurut Trisnayana et al. (2016), tenun juga merupakan salah satu jenis seni kriya nusantara yaitu kriya tekstil.

Tenun Kubang H. Ridwan BY merupakan salah satu usaha tenun yang sudah berkembang di Kabupaten Lima Puluh Kota, Sumatera Barat. Sejak tahun 1961 sampai sekarang, telah banyak produk yang dihasilkan beserta motif-motif yang menarik, sehingga bisa mencapai pangsa pasar yang luas sampai ke luar negeri. Menurut Setiawan \& Suwarningdyah (2014), salah satu indikasi berkembangnya suatu usaha kerajinan adalah banyaknya populasi jumlah pengrajin yang menekuni bidang tersebut. Hal ini sesuai dengan keadaan usaha tenun Kubang $\mathrm{H}$. Ridwan BY yang terobservasi saat survey awal bahwa memiliki pengrajin sekitar 25 orang yang didukung alat tenun memadai.
Pengemasan adalah salah satu elemen produk yang membedakannya dari pesaing, sehingga orientasi konsumen lebih fokus pada kemasan (Lal et al., 2015). Kemasan juga bisa dimanfaatkan sebagai teknik meningkatkan kualitas produk (Saeed et al., 2010). Dengan demikian, kemasan adalah atribut produk yang dibutuhkan dan bernilai bagi konsumen (Utami et al., 2016).

Persepsi kualitas merupakan penilaian konsumen mengenai keunggulan produk yang didasarkan pada persepsi subjektif (Erdoğmuş \& Büdeyri-Turan, 2012). Niat membeli konsumen ditentukan oleh kualitas produk, dimana jika kualitas produk tinggi maka niat membeli konsumen terhadap produk juga tinggi (Saleem et al., 2015). Karena itu, persepsi kualitas berpengaruh terhadap niat membeli (Kar et al., 2018).

Persepsi nilai adalah hasil penilaian pelanggan untuk penerimaan harga dan nilai suatu produk (Wang, 2013). Persepsi nilai bisa dianggap sebagai pertukaran antara manfaat apa yang diterima konsumen dengan pengorbanan apa yang diberikanya dalam pertukaran pasar (Chen, 2013). Persepsi nilai berpengaruh terhadap niat membeli konsumen (Beneke et al., 2013).

Kemasan Tenun Kubang H. Ridwan BY sudah cukup lama diluncurkan dan selama ini belum pernah dievaluasi bagaimana persepsi konsumen terhadap kemasan tersebut. Produk tenun Kubang H. Ridwan By telah memperbaiki kualitas dan membidik segmen menengah dan atas. Selain itu, pemilik terus meningkatkan nilai produknya. Oleh karena itu, dinilai diperlukan upaya penelitian terkait dengan fenomena yang telah diuraikan. Dengan demikian, penelitian ini bertujuan untuk menganalisis perceived packaging, perceived value, perceived quality dan purchase intention pada Tenun Kubang $\mathrm{H}$. Ridwan BY di Kabupaten Lima Puluh Kota. 


\section{Perceived Packaging}

Kemasan produk merupakan satu faktor penting lain yang mengawal nilai yang dirasakan produk (Shafiq et al., 2011). Kemasan produk memiliki pengaruh kuat atas persepsi nilai konsumen, sehingga menghasilkan niat membeli (Baskaran et al., 2017). Kemasan produk juga merupakan atribut utama dari nilai yang dirasakan pelanggan dari produk. Ketertarikan pelanggan diperoleh melalui aspek kemasan, sehingga pihak desainer harus mempertimbangkan emosi dalam membuat desain kemasan (Shafiq et al., 2011).

Pengemasan adalah bagian penting dari reputasi perusahaan yang memainkan peran utama dalam menunjukkan produk yang berkualitas (Shafiq et al., 2011). Pengemasan bukan hanya sebagai sarana untuk pengiriman yang aman, tetapi juga merupakan salah satu alat pemasaran untuk mengkomunikasikan pesan merek kepada konsumen (Hellström \& Nilsson, 2011). Selain itu, pengemasan dari produk juga salah satu alat komunikasi pemasaran yang berkelanjutan (Shafiq et al., 2011). Visual kemasan bisa menarik perhatian konsumen untuk menciptakan persepsi akan produk (Venter et al., 2011), sebab kemasan berperan dalam menentukan pasar produk (Brommer et al., 2011). Persepsi kemasan juga mendorong niat membeli konsumen (Baskaran et al., 2017; Mirabi et al., 2015; Younus et al., 2015; Kar et al., 2018).

Kemasan produk bisa meningkatkan kesadaran pelanggan atas produk. Hal ini disebabkan pelanggan bergantung kepada kemasan produk. Setiap perusahaan harus bisa menunjukkan manfaat dan fitur produk yang akan menambah pengetahuan pelanggan (Younus et al., 2015), sehingga pada akhirnya bisa meningkatkan niat beli dari pelanggan.

\section{Perceived Value}

Persepsi nilai adalah perkiraan sebelum pembelian produk berkenaan dengan kualitas, harga, dan desain (Shafiq et al., 2011). Peningkatan pengetahuan produk, desain, dan pengemasan produk yang menarik mengarah pada nilai yang dirasakan. Semakin tinggi nilai yang dirasakan tentang produk, maka semakin tinggi tingkat pembelian produk (Shafiq et al. 2011).

Pengetahuan tentang produk digunakan konsumen di dalam proses penilaian dan evaluasi untuk membuat keputusan suatu pembelian. Persepsi nilai akan mengarahkan pelanggan terhadap niat pembelian, sebab pelanggan memperkirakan nilai dari produk melalui berbagai sumber, salah satunya adalah kemasan produk (Shafiq et al., 2011). Selain itu, nilai yang dirasakan menurut Lomboan (2017) adalah konsep multidimensi dan mempunyai struktur yang dinamis. Sehingga disimpulkan bahwa persepsi nilai adalah nilai suatu produk yang ditentukan oleh pendapat pelanggan mengenai nilainya. Selain itu, persepsi nilai juga berdampak terhadap niat membeli konsumen (Kim et al., 2013; Ha \& Jang, 2010; Konuk, 2018; Beneke et al., 2015; Gendel-Guterman \& Levy, 2013; Lee et al., 2019).

Persepsi nilai merupakan sumber keunggulan bersaing (Mulki \& Jaramillo, 2011). Ada empat karakteristik mengenai nilai pelanggan, yaitu: merupakan konsep subjektif, kesenjangan antara manfaat dan pengorbanan, manfaat dan pengorbanan, dan persepsi nilai (Chen, 2013). Persepsi nilai mendahului kepuasan pelanggan sehingga mereka mendapatkan manfaat, kualitas, dan nilai. Hal ini membuat pelanggan bersedia membayar harga, biaya, dan pengorbanan.

\section{Perceived Quality}

Persepsi kualitas mengacu kepada penilaian pelanggan atas keunggulan produk yang dipertimbangkan (Wang, 2013). Persepsi kualitas memberikan nilai tambah bagi konsumen. Menurut Khattak \& Shah 
(2011), konsumen dari negara berkembang akan mendukung produk non lokal karena dianggap berkualitas tinggi. Sikap konsumen terhadap visual kemasan juga mempunyai efek langsung terhadap persepsi kualitas (Wang, 2013). Menurut Nilforushan \& Haeri (2015), kualitas yang dirasakan adalah keseluruhan persepsi kualitas pelanggan yang sesuai dengan tujuan yang diharapkan.

Persepsi kualitas adalah penilaian subjektif konsumen terhadap kualitas produk, dimana konsumen akan mengevaluasi kualitas produk dari pengalaman dan perasaan mereka sebelumnya (Lomboan, 2017). Kualitas yang dirasakan juga merupakan karakteristik subjektif yang penting, serta petunjuk informasi dan perilaku yang disadari (Ansari \& Riasi, 2016). Persepsi kualitas mempunyai dampak langsung pada niat membeli (Musharraf \& Ali, 2013; Tsiotsou, 2006; Mirabi et al., 2015; Li et al., 2013; Kar et al., 2018; Younus et al., 2015; Quintal et al., 2016; Saleem et al,. 2015; Saeed \& Grunert, 2014; Jalilvand et al., 2011).

\section{Purchase Intention}

Niat membeli merupakan preferensi konsumen untuk membeli produk barang atau layanan (Younus et al., 2015). Niat membeli mempunyai aspek lain seperti konsumen akan membeli produk setelah melakukan evaluasi. Terdapat banyak faktor yang mempengaruhi niat konsumen di dalam memilih produk, dimana keputusan akhir tergantung pada niat konsumen.

Menurut Younus et al. (2015), banyak faktor yang mampu mempengaruhi niat untuk membeli, diantaranya adalah: pengetahuan pelanggan, persepsi konsumen, pengemasan produk dan lain-lain. Niat pembelian sering digunakan untuk memperkirakan penjualan produk dan layanan yang ada (Asshidin et al.,
2016). Niat membeli adalah kemungkinan kesiapan konsumen untuk membeli produk dalam waktu dekat yang terkait dengan sikap, persepsi konsumen, dan perilaku pembelian (Wu et al., 2011). Niat membeli adalah faktor penting bagi konsumen untuk membuat keputusan pembelian produk (Musharraf \& Ali, 2013). Karena itu, niat membeli harus dipertimbangkan ketika mempelajari perilaku pembelian konsumen. Niat perilaku telah di uji di studi sebelumnya dalam pengambilan keputusan oleh konsumen (Zarantonello \& Schmitt, 2010). Keyakinan konsumen, sikap, emosi, serta pengalaman sebelumnya berdampak pada niat pembelian (Ilicic \& Webster, 2011).

\section{METODE PENELITIAN}

Jenis penelitian ini adalah penelitian deskriptif, yang bertujuan untuk mengetahui dan menjadi mampu dalam menjelaskan karakteristik variabel yang diteliti dalam suatu situasi (Sekaran \& Bougie, 2016). Pendekatan kuantitatif digunakan untuk mengamati, mengumpulkan data, dan menyajikan analisis dalam penelitian. Teknik pengumpulan data menggunakan kuesioner dengan skala Likert, sedangkan teknik pengambilan sampel menggunakan convenience sampling (Sekaran \& Bougie, 2016).

Dalam penelitian ini, unit analisis adalah konsumen yang pernah ataupun belum pernah bertransaksi dengan Tenun Kubang $\mathrm{H}$. Ridwan BY, tetapi familiar dengan Tenun Kubang H. Ridwan BY. Ukuran sampel minimal ditentukan dengan menggunakan jumlah indikator dikalikan 5-10 (Hair et al., 2011). Dalam penelitian ini terdapat 19 indikator, sehingga ukuran sampel penelitian yaitu 19 × $5=95$ sampel. Metode analisis data menggunakan teknik distribusi frekuensi, yaitu menganalisis nilai rata-rata jawaban. 
Tabel 1. Karakteristik Responden

\begin{tabular}{|c|c|c|c|}
\hline Kategori & Deskripsi & Frekuensi (org) & Frekuensi (\%) \\
\hline \multirow[t]{2}{*}{ Jenis Kelamin } & Laki-Laki & 33 & 35 \\
\hline & Perempuan & 62 & 65 \\
\hline \multirow[t]{6}{*}{ Pekerjaan } & Siswa / Mahasiswa & 10 & 10 \\
\hline & Karyawan Swasta & 14 & 15 \\
\hline & Petani / Nelayan & 6 & 6 \\
\hline & PNS / TNI / Polisi & 22 & 23 \\
\hline & Wiraswasta & 12 & 13 \\
\hline & Lainnya & 31 & 33 \\
\hline \multirow[t]{6}{*}{ Pendidikan Terakhir } & Tamatan SD & 6 & 6 \\
\hline & Tamatan SMP & 7 & 7 \\
\hline & Tamatan SMA & 34 & 36 \\
\hline & Tamatan Akademi (D3) & 16 & 17 \\
\hline & Tamatan Sarjana (S1) & 29 & 31 \\
\hline & Tamatan Pasca Sarjana (S2 / S3) & 3 & 3 \\
\hline \multirow[t]{6}{*}{ Pendapatan / bulan } & Kurang dari Rp. 2.000 .000 & 34 & 36 \\
\hline & Rp. $2.000 .000-$ Rp. 4.000 .000 & 15 & 16 \\
\hline & Rp. $4.000 .001-$ Rp. 6.000 .000 & 29 & 30 \\
\hline & Rp. $6.000 .001-$ Rp. 8.000 .000 & 13 & 14 \\
\hline & Rp. 8.000.001 - Rp. 10.000.000 & 3 & 3 \\
\hline & Lebih dari Rp. 10.000 .000 & 1 & 1 \\
\hline \multirow[t]{2}{*}{ Membeli Produk } & Pernah & 73 & 77 \\
\hline & Tidak Pernah & 22 & 23 \\
\hline \multirow[t]{5}{*}{ Frekuensi Pembelian } & Tidak Pernah & 22 & 23 \\
\hline & 1 kali & 43 & 46 \\
\hline & 2 kali & 24 & 25 \\
\hline & 3 kali & 0 & 0 \\
\hline & Lebih dari 3 kali & 6 & 6 \\
\hline
\end{tabular}

Sumber: Data primer diolah, 2019.

\section{HASIL ANALISIS}

\section{Karakteristik Responden}

Karakteristik dari para responden dalam penelitian ini dijelaskan dalam Tabel 1 . Berdasarkan data pada Tabel 1 terlihat bahwa mayoritas perempuan yang menjadi responden dalam penelitian ini, yaitu sebanyak 33 orang atau 35 persen. Hal ini mengindikasikan bahwa perempuan lebih cenderung suka berbelanja dibandingkan laki- laki, terutama dalam bidang fashion seperti produk Tenun Kubang H.Ridwan BY.

Tabel 1 berikutnya menunjukkan bahwa mayoritas responden penelitian ini memiliki jenis pekerjaan lainnya atau yang tidak dinyatakan secara eksplisit sebagai alternatif jawaban, yaitu sebanyak 31 orang atau 33 persen. Kategori pekerjaan lainnya itu seperti: ibu rumah tangga, pensiunan PNS, tidak bekerja, kerja sampingan, dan lain-lain. 
Berkaitan dengan pendidikan terakhir, Tabel 1 menunjukkan mayoritas responden adalah Tamatan SMA atau sederajat, yaitu sebanyak 34 orang atau 36 persen. Sementara itu, mayoritas responden penelitian ini memiliki pendapatan per bulan sebesar kurang dari Rp. 2.000.000,- yaitu sebanyak 34 orang atau 36 persen.

Terkait aktivitas pembelian produk yang dianalisis, mayoritas responden penelitian ini menyatakan pernah membeli daripada hanya menanyakan informasi saja, yaitu sebanyak 73 orang atau 77 persen. Sayangnya, Tabel 1 juga menunjukkan fakta bahwa mayoritas responden menyatakan baru membeli produk Tenun Kubang H. Ridwan BY sebanyak satu kal, yaitu 43 orang atau 46 persen. Kondisi ini dinilai sangat disayangkan terjadi karena menunjukkan relatif masih rendahnya minat konsumen untuk membeli produk Tenun Kubang H. Ridwan BY ataupun kemungkinan adanya kualitas dan nilai dari produk Tenun Kubang tersebut yang dipandang kurang memenuhi ekspektasi konsumen.

\section{Hasil Analisis Perceived Packaging}

Pada bagian ini dianalisis hasil pendapat responden penelitian ini mengenai variabel perceived packaging yang ditunjukkan dalam Tabel 2.

Pada Tabel 2 terlihat alternatif "Kurang Setuju" maupun "Setuju" merupakan jawaban dari mayoritas responden untuk pernyataan Nomor 1 tentang kemungkinan mereka membeli produk Tenun Kubang H. Ridwan BY karena mempunyai kemasan yang menarik, yaitu sebanyak 38 orang atau 40 persen. Secara rata-rata diperoleh nilai 3,36 atau lebih mendekati nilai 3, atau pendapat responden mengenai pernyataan Nomor 1 adalah berada pada skala "Kurang Setuju" bahwa kemungkinan mereka membeli produk Tenun Kubang H. Ridwan BY karena mempunyai kemasan yang menarik.
Hal ini juga terjadi pada jawaban dari mayoritas responden untuk pernyataan Nomor 2 mengenai kemasan produk Tenun Kubang H. Ridwan BY dinilai menyerupai dengan kemasan produk pesaing, yaitu pada alternatif "Tidak Setuju" maupun "Kurang Setuju" sebanyak 34 orang atau 36 persen. Secara rata-rata diperoleh nilai 2,87 atau lebih mendekati nilai 3, atau bahwa pendapat responden mengenai pernyataan Nomor 2 adalah berada pada skala "Kurang Setuju" terkait pernyataan kemasan produk Tenun Kubang H. Ridwan BY dinilai mirip dengan kemasan produk pesaing.

Pada pernyataan Nomor 3 mengenai pendapat bahwa kemasan produk Tenun Kubang H. Ridwan BY sama bagusnya dengan kemasan produk pesaing, mayoritas responden menjawab "Kurang Setuju" yaitu sebanyak 43 orang atau 46 persen. Secara rata-rata diperoleh nilai 2,99 atau lebih mendekati nilai 3, atau bahwa pendapat responden mengenai pernyataan Nomor 2 adalah berada pada skala "Kurang Setuju" bahwa kemasan produk Tenun Kubang $\mathrm{H}$. Ridwan BY sama bagusnya dengan kemasan produk pesaing.

Selanjutnya, pada pernyataan Nomor 4 mengenai pendapat bahwa kemasan produk Tenun Kubang H. Ridwan BY menampilkan cara pemeliharaan produk, mayoritas dari responden menjawab "Setuju" yaitu sebanyak 49 orang atau 52 persen. Secara rata-rata diperoleh nilai 3,67 atau lebih mendekati nilai 4 , atau bahwa pendapat responden mengenai pernyataan Nomor 4 adalah berada pada skala "Setuju" bahwa kemasan produk Tenun Kubang H. Ridwan BY menampilkan cara pemeliharaan produk.

Untuk pernyataan Nomor 5 mengenai pendapat bahwa kemasan produk Tenun Kubang H. Ridwan BY terlihat lebih sulit (susah dibuka) dibandingkan kemasan produk pesaing, mayoritas dari responden menjawab 
"Tidak Setuju" yaitu sebanyak 56 orang atau 59 persen. Secara rata-rata diperoleh nilai 2,51 atau lebih mendekati nilai 3, atau bahwa pendapat responden mengenai pernyataan Nomor 5 adalah berada pada skala "Kurang Setuju" bahwa kemasan produk Tenun Kubang H. Ridwan BY terlihat lebih sulit (susah dibuka) dibandingkan kemasan produk pesaing.

Pada pernyataan Nomor 6 mengenai pendapat bahwa kemasan produk Tenun Kubang H. Ridwan BY menjamin keamanan produk, mayoritas dari responden menjawab "Setuju" yaitu sebanyak 47 orang atau 49 persen. Secara rata-rata diperoleh nilai 3,69 atau lebih mendekati nilai 4 , atau bahwa pendapat responden mengenai pernyataan Nomor 6 adalah berada pada skala "Setuju" bahwa kemasan produk Tenun Kubang $\mathrm{H}$. Ridwan BY menjamin keamanan produk.

Pada pernyataan Nomor 7 mengenai pendapat bahwa kemasan produk Tenun Kubang H. Ridwan BY mengurangi kemungkinan kerusakan produk, mayoritas responden menjawab "Setuju" yaitu sebanyak 45 orang atau 47 persen. Secara rata-rata diperoleh nilai 3,61 atau lebih mendekati nilai 4, atau bahwa pendapat responden mengenai pernyataan Nomor 6 adalah berada pada skala "Setuju" bahwa kemasan produk Tenun Kubang $\mathrm{H}$. Ridwan BY mengurangi kerusakan produk.

Tabel 2. Hasil Pendapat Responden tentang Perceived Packaging

\begin{tabular}{|c|c|c|c|c|c|c|c|c|c|c|c|c|c|}
\hline \multirow{2}{*}{ No. } & \multirow{2}{*}{ Indikator } & \multicolumn{2}{|c|}{ STS } & \multicolumn{2}{|c|}{$\mathrm{TS}$} & \multicolumn{2}{|c|}{$\mathrm{KS}$} & \multicolumn{2}{|c|}{$\mathrm{S}$} & \multicolumn{2}{|c|}{ SS } & \multirow{2}{*}{$\begin{array}{c}\text { Total } \\
\text { F }\end{array}$} & \multirow{2}{*}{ Rerata } \\
\hline & & $\mathrm{F}$ & $\%$ & $\mathrm{~F}$ & $\%$ & $\mathrm{~F}$ & $\%$ & $\mathrm{~F}$ & $\%$ & $\mathrm{~F}$ & $\%$ & & \\
\hline 1 & $\begin{array}{l}\text { Saya mungkin akan membeli } \\
\text { produk "Tenun Kubang H. } \\
\text { Ridwan BY" karena } \\
\text { mempunyai kemasan yang } \\
\text { menarik. }\end{array}$ & 0 & 0 & 14 & 15 & 38 & 40 & 38 & 40 & 5 & 5 & 95 & 3,36 \\
\hline 2 & $\begin{array}{l}\text { Kemasan produk "Tenun } \\
\text { Kubang H. Ridwan BY" mirip } \\
\text { dengan kemasan produk } \\
\text { pesaing. }\end{array}$ & 2 & 2 & 34 & 36 & 34 & 36 & 24 & 25 & 1 & 1 & 95 & 2,87 \\
\hline 3 & $\begin{array}{l}\text { Kemasan produk "Tenun } \\
\text { Kubang H. Ridwan BY" sama } \\
\text { bagusnya dengan kemasan } \\
\text { produk pesaing. }\end{array}$ & 4 & 4 & 22 & 23 & 43 & 46 & 23 & 24 & 3 & 3 & 95 & 2,99 \\
\hline 4 & $\begin{array}{l}\text { Kemasan produk "Tenun } \\
\text { Kubang H. Ridwan BY" } \\
\text { menampilkan cara } \\
\text { pemeliharaan produk. }\end{array}$ & 0 & 0 & 9 & 9 & 25 & 26 & 49 & 52 & 12 & 13 & 95 & 3,67 \\
\hline 5 & $\begin{array}{l}\text { Kemasan produk "Tenun } \\
\text { Kubang H. Ridwan BY" terlihat } \\
\text { lebih sulit (susah dibuka) dari } \\
\text { kemasan produk pesaing. }\end{array}$ & 5 & 5 & 56 & 59 & 18 & 19 & 13 & 14 & 3 & 3 & 95 & 2,51 \\
\hline 6 & $\begin{array}{l}\text { Kemasan produk "Tenun } \\
\text { Kubang H. Ridwan BY" } \\
\text { menjamin keamanan produk. }\end{array}$ & 0 & 0 & 3 & 3 & 34 & 36 & 47 & 49 & 11 & 12 & 95 & 3,69 \\
\hline 7 & $\begin{array}{l}\text { Kemasan produk "Tenun } \\
\text { Kubang H. Ridwan BY" } \\
\text { mengurangi kerusakan produk. }\end{array}$ & 0 & 0 & 7 & 7 & 33 & 35 & 45 & 47 & 10 & 11 & 95 & 3,61 \\
\hline
\end{tabular}

Ket: STS = Sangat Tidak Setuju; S = Tidak Setuju; KS = Kurang Setuju; S = Setuju; SS = Sangat Setuju.

Sumber: Data primer diolah, 2019. 
Tabel 3. Hasil Pendapat Responden tentang Perceived Value

\begin{tabular}{|c|c|c|c|c|c|c|c|c|c|c|c|c|c|}
\hline \multirow{2}{*}{ No. } & \multirow{2}{*}{ Indikator } & \multicolumn{2}{|c|}{ STS } & \multicolumn{2}{|c|}{ TS } & \multicolumn{2}{|c|}{$\mathrm{KS}$} & \multicolumn{2}{|c|}{$S$} & \multicolumn{2}{|c|}{ SS } & \multirow{2}{*}{$\begin{array}{c}\text { Total } \\
\text { F }\end{array}$} & \multirow{2}{*}{ Rerata } \\
\hline & & $\mathrm{F}$ & $\%$ & $\mathrm{~F}$ & $\%$ & F & $\%$ & $\mathrm{~F}$ & $\%$ & $\mathrm{~F}$ & $\%$ & & \\
\hline 1 & $\begin{array}{l}\text { Manfaat dari produk "Tenun } \\
\text { Kubang H. Ridwan BY" } \\
\text { sebanding dengan nilai uang } \\
\text { yang dibayarkan. }\end{array}$ & 2 & 2 & 2 & 2 & 24 & 25 & 48 & 51 & 19 & 20 & 95 & 3,84 \\
\hline 2 & $\begin{array}{l}\text { Produk "Tenun Kubang H. } \\
\text { Ridwan BY" menawarkan } \\
\text { harga yang wajar. }\end{array}$ & 0 & 0 & 2 & 2 & 29 & 31 & 56 & 59 & 8 & 8 & 95 & 3,74 \\
\hline 3 & $\begin{array}{l}\text { Secara keseluruhan, produk } \\
\text { "Tenun Kubang H. Ridwan } \\
\text { BY" sangat bernilai tinggi. }\end{array}$ & 0 & 0 & 3 & 3 & 36 & 38 & 41 & 43 & 15 & 16 & 95 & 4,02 \\
\hline
\end{tabular}

Ket: STS = Sangat Tidak Setuju; S = Tidak Setuju; KS = Kurang Setuju; S = Setuju; SS = Sangat Setuju.

Sumber: Data primer diolah, 2019.

Berdasarkan Tabel 2 maka dirangkum bahwa rata-rata responden menyatakan kurang setuju bahwa mereka membeli Tenun Kubang H. Ridwan BY karena alasan bahwa kemasan produk tersebut memiliki daya tarik, mirip dengan kemasan produk pesaing, sama bagusnya dengan kemasan produk, serta terlihat lebih sulit (susah dibuka) dibandingkan kemasan produk pesaing. Sebaliknya, rata-rata responden penelitian ini menyatakan setuju bahwa mereka membeli Tenun Kubang H. Ridwan BY karena alasan bahwa kemasan produk itu menampilkan cara pemeliharaan produk, menjamin keamanan produk, serta mengurangi kerusakan produk.

\section{Hasil Analisis Perceived Value}

Berikutnya dianalisis hasil pendapat responden penelitian ini mengenai variabel perceived value yang ditunjukkan dalam Tabel 3.

Pada Tabel 3 ditunjukkan jawaban dari mayoritas responden untuk pernyataan Nomor 1 bahwa manfaat dari produk Tenun Kubang H. Ridwan BY adalah sebanding dengan nilai uang yang dibayarkan berada pada kategori "Setuju", yaitu sebanyak 48 orang atau 51 persen. Secara rata-rata diperoleh nilai 3,84 atau lebih mendekati nilai 4 , atau pendapat responden mengenai pernyataan Nomor 1 adalah berada pada skala "Setuju" bahwa manfaat dari produk Tenun Kubang $\mathrm{H}$. Ridwan BY yang mereka rasakan adalah sebanding dengan nilai uang yang mereka bayarkan untuk memperolehnya.

Pada pernyataan Nomor 2 mengenai pendapat bahwa produk Tenun Kubang $\mathrm{H}$. Ridwan BY menawarkan harga yang wajar, mayoritas dari responden menjawab "Setuju" yaitu sebanyak 56 orang atau 59 persen. Secara rata-rata diperoleh nilai 3,74 atau lebih mendekati nilai 4, atau bahwa pendapat responden mengenai pernyataan Nomor 2 adalah berada pada skala "Setuju" bahwa produk Tenun Kubang H. Ridwan BY menawarkan harga yang wajar.

Untuk pernyataan Nomor 3 mengenai pendapat bahwa secara keseluruhan, produk Tenun Kubang H. Ridwan BY sangat bernilai tinggi, mayoritas dari responden menjawab "Setuju" yaitu sebanyak 41 orang atau 43 persen. Secara rata-rata diperoleh nilai 4,02 atau lebih mendekati nilai 4 , atau bahwa pendapat responden mengenai pernyataan Nomor 3 adalah berada pada skala "Setuju" bahwa produk Tenun Kubang H. Ridwan BY secara keseluruhan memiliki nilai (value) yang sangat tinggi. 
Tabel 4. Hasil Pendapat Responden tentang Perceived Quality

\begin{tabular}{|c|c|c|c|c|c|c|c|c|c|c|c|c|c|}
\hline \multirow{2}{*}{ No. } & \multirow{2}{*}{ Indikator } & \multicolumn{2}{|c|}{ STS } & \multicolumn{2}{|c|}{$\mathrm{TS}$} & \multicolumn{2}{|c|}{$\mathrm{KS}$} & \multicolumn{2}{|c|}{$S$} & \multicolumn{2}{|c|}{ SS } & \multirow{2}{*}{$\begin{array}{c}\text { Total } \\
\text { F }\end{array}$} & \multirow{2}{*}{ Rerata } \\
\hline & & $\mathrm{F}$ & $\%$ & $\mathrm{~F}$ & $\%$ & $\mathrm{~F}$ & $\%$ & $\mathrm{~F}$ & $\%$ & $\mathrm{~F}$ & $\%$ & & \\
\hline 1 & $\begin{array}{l}\text { Merek "Tenun Kubang H. } \\
\text { Ridwan BY" berkualitas } \\
\text { tinggi. }\end{array}$ & 0 & 0 & 6 & 6 & 33 & 35 & 49 & 52 & 7 & 7 & 95 & 3,60 \\
\hline 2 & $\begin{array}{l}\text { Sepertinya Merek "Tenun } \\
\text { Kubang H. Ridwan BY" } \\
\text { mungkin sangat berkualitas. }\end{array}$ & 0 & 0 & 6 & 6 & 42 & 44 & 45 & 48 & 2 & 2 & 95 & 3,45 \\
\hline 3 & $\begin{array}{l}\text { Merek "Tenun Kubang H. } \\
\text { Ridwan BY" mungkin bisa } \\
\text { mempertahankan kualitasnya. }\end{array}$ & 0 & 0 & 2 & 2 & 31 & 32 & 50 & 53 & 12 & 13 & 95 & 3,76 \\
\hline 4 & $\begin{array}{l}\text { Merek "Tenun Kubang H. } \\
\text { Ridwan BY" mungkin } \\
\text { memiliki keunikan dibanding } \\
\text { merek pesaing. }\end{array}$ & 1 & 1 & 4 & 4 & 24 & 25 & 50 & 53 & 16 & 17 & 95 & 3,80 \\
\hline
\end{tabular}

Ket: STS = Sangat Tidak Setuju; S = Tidak Setuju; KS = Kurang Setuju; S = Setuju; SS = Sangat Setuju.

Sumber: Data primer diolah, 2019.

\section{Hasil Analisis Perceived Quality}

Hasil pendapat responden penelitian ini tentang variabel perceived quality dirangkum dalam Tabel 4.

Hasil jawaban dari mayoritas responden untuk pernyataan Nomor 1 bahwa merek Tenun Kubang H. Ridwan BY berkualitas tinggi, pada Tabel 4 ditunjukkan berada pada kategori "Setuju", yaitu sebanyak 49 orang atau 52 persen. Secara rata-rata diperoleh nilai 3,60 atau lebih mendekati nilai 4, atau pendapat responden mengenai pernyataan Nomor 1 adalah berada pada skala "Setuju" bahwa merek Tenun Kubang H. Ridwan BY berkualitas tinggi.

Berikutnya, untuk pernyataan Nomor 2 mengenai pendapat bahwa merek Tenun Kubang H. Ridwan BY sepertinya sangat berkualitas, mayoritas responden menjawab "Setuju" yaitu sebanyak 45 orang atau 48 persen. Secara rata-rata diperoleh nilai 3,45 atau lebih mendekati nilai 4, atau bahwa pendapat responden mengenai pernyataan Nomor 2 adalah berada pada skala "Setuju" bahwa merek Tenun Kubang H. Ridwan BY dinilai sepertinya sangat berkualitas.
Pada pernyataan Nomor 3 mengenai pendapat bahwa merek Tenun Kubang $\mathrm{H}$. Ridwan BY mungkin bisa mempertahankan kualitasnya, mayoritas responden menjawab "Setuju" yaitu sebanyak 50 orang atau 53 persen. Secara rata-rata diperoleh nilai 3,76 atau lebih mendekati nilai 4, atau bahwa pendapat responden mengenai pernyataan Nomor 3 adalah berada pada skala "Setuju" bahwa merek Tenun Kubang H. Ridwan BY mungkin bisa mempertahankan kualitasnya.

Untuk pernyataan Nomor 4 mengenai pendapat bahwa merek Tenun Kubang $\mathrm{H}$. Ridwan BY mungkin memiliki keunikan dibandingkan dengan merek pesaing, mayoritas responden menjawab "Setuju" yaitu sebanyak 50 orang atau 53 persen. Secara rata-rata diperoleh nilai 3,80 atau lebih mendekati nilai 4 , atau bahwa pendapat responden mengenai pernyataan Nomor 3 adalah berada pada skala "Setuju" bahwa merek Tenun Kubang $\mathrm{H}$. Ridwan BY mungkin memiliki keunikan dibandingkan dengan merek pesaing. 
Tabel 5. Hasil Pendapat Responden tentang Purchase Intention

\begin{tabular}{|c|c|c|c|c|c|c|c|c|c|c|c|c|c|}
\hline \multirow{2}{*}{ No. } & \multirow{2}{*}{ Indikator } & \multicolumn{2}{|c|}{ STS } & \multicolumn{2}{|c|}{ TS } & \multicolumn{2}{|c|}{ KS } & \multicolumn{2}{|c|}{$S$} & \multicolumn{2}{|c|}{ SS } & \multirow{2}{*}{$\begin{array}{c}\text { Total } \\
\text { F }\end{array}$} & \multirow{2}{*}{ Rerata } \\
\hline & & $\mathrm{F}$ & $\%$ & $\mathrm{~F}$ & $\%$ & $\mathrm{~F}$ & $\%$ & $\mathrm{~F}$ & $\%$ & $\mathrm{~F}$ & $\%$ & & \\
\hline 1 & $\begin{array}{l}\text { Saya akan mempertimbang- } \\
\text { kan membeli produk "Tenun } \\
\text { Kubang H. Ridwan BY". }\end{array}$ & 0 & 0 & 10 & 11 & 33 & 35 & 43 & 45 & 9 & 9 & 95 & 3,54 \\
\hline 2 & $\begin{array}{l}\text { Mungkin saya akan membeli } \\
\text { produk "Tenun Kubang H. } \\
\text { Ridwan BY". }\end{array}$ & 0 & 0 & 4 & 4 & 18 & 19 & 54 & 57 & 19 & 20 & 95 & 3,93 \\
\hline 3 & $\begin{array}{l}\text { Saya bersedia membeli } \\
\text { produk "Tenun Kubang H. } \\
\text { Ridwan By" untuk } \\
\text { memenuhi kebutuhan saya. }\end{array}$ & 0 & 0 & 6 & 6 & 29 & 31 & 44 & 46 & 16 & 17 & 95 & 3,74 \\
\hline 4 & $\begin{array}{l}\text { Saya bersedia untuk me- } \\
\text { rekomendasikan produk } \\
\text { "Tenun Kubang H. Ridwan } \\
\text { BY" kepada teman saya. }\end{array}$ & 0 & 0 & 7 & 7 & 20 & 21 & 47 & 50 & 21 & 22 & 95 & 3,86 \\
\hline 5 & $\begin{array}{l}\text { Saya akan berusaha mencari } \\
\text { informasi tentang produk } \\
\text { "Tenun Kubang H. Ridwan } \\
\text { BY". }\end{array}$ & 0 & 0 & 9 & 9 & 36 & 38 & 39 & 41 & 11 & 12 & 95 & 3,55 \\
\hline
\end{tabular}

Ket: STS = Sangat Tidak Setuju; S = Tidak Setuju; KS = Kurang Setuju; S = Setuju; SS = Sangat Setuju.

Sumber: Data primer diolah, 2019.

\section{Hasil Analisis Purchase Intention}

Hasil pendapat responden penelitian ini mengenai variabel purchase intention dirangkum dalam Tabel 5.

Tabel 5 menunjukkan hasil jawaban dari mayoritas responden untuk pernyataan Nomor 1 bahwa mereka akan mempertimbangkan membeli produk Tenun Kubang H. Ridwan BY berada pada kategori "Setuju", yaitu sebanyak 43 orang atau 45 persen. Secara rata-rata diperoleh nilai 3,54 atau lebih mendekati nilai 4, atau pendapat responden mengenai pernyataan Nomor 1 adalah berada pada skala "Setuju" bahwa mereka secara individual akan mempertimbangkan membeli produk Tenun Kubang H. Ridwan BY.

Pada pernyataan Nomor 2 mengenai pendapat mungkin mereka akan membeli produk Tenun Kubang H. Ridwan BY, mayoritas responden menjawab "Setuju" yaitu sebanyak 54 orang atau 57 persen. Secara rata-rata diperoleh nilai 3,93 atau lebih mendekati nilai 4 , ataupun bahwa pendapat responden mengenai pernyataan Nomor 2 adalah berada pada skala "Setuju" bahwa mereka secara individu mungkin membeli produk Tenun Kubang H. Ridwan BY.

Berikutnya, pada pernyataan Nomor 3 mengenai pendapat bahwa mereka bersedia membeli produk Tenun Kubang H. Ridwan BY untuk memenuhi kebutuhan mereka, mayoritas responden menjawab "Setuju" yaitu sebanyak 44 orang atau 46 persen. Secara rata-rata diperoleh nilai 3,74 atau lebih mendekati nilai 4 , ataupun bahwa pendapat responden mengenai pernyataan Nomor 3 adalah berada pada skala "Setuju" bahwa mereka bersedia membeli produk Tenun Kubang H. Ridwan BY untuk memenuhi kebutuhan mereka.

Untuk pernyataan Nomor 4 mengenai pendapat bahwa mereka bersedia untuk merekomendasikan produk Tenun Kubang $\mathrm{H}$. Ridwan BY kepada teman mereka, mayoritas responden menjawab "Setuju" yaitu sebanyak 47 orang atau 50 persen. Secara rata-rata 
diperoleh nilai 3,86 atau lebih mendekati nilai 4, atau bahwa pendapat responden mengenai pernyataan Nomor 4 adalah berada pada skala "Setuju" bahwa mereka bersedia merekomendasikan produk Tenun Kubang H. Ridwan BY kepada teman mereka.

Terakhir, pada pernyataan Nomor 5 mengenai pendapat bahwa mereka akan berusaha mencari informasi tentang produk Tenun Kubang H. Ridwan BY, mayoritas responden menjawab "Setuju" yaitu sebanyak 39 orang atau 41 persen. Secara rata-rata diperoleh nilai 3,55 atau lebih mendekati nilai 4, atau bahwa pendapat responden mengenai pernyataan Nomor 5 adalah berada pada skala "Setuju" bahwa mereka bersedia berusaha mencari informasi tentang produk Tenun Kubang H. Ridwan BY.

\section{Pembahasan}

Berdasarkan hasil penelitian didapatkan beberapa temuan terkait perceived packaging, perceived value, perceived quality, dan purchase intention. Pertama, pada variabel perceived packaging diperoleh rata-rata jawaban tertinggi terjadi pada item pernyataan keenam, yaitu kemasan produk Tenun Kubang H. Ridwan BY menjamin keamanan produk. Temuan ini mengindikasikan bahwa responden menilai kemasan yang ada sudah aman bagi produk tenun. Hal ini didukung dengan adanya petunjuk pemeliharaan produk yang tertera pada kemasan, sehingga membantu konsumen bagaimana cara menyimpan produk dengan baik dan aman. Packaging yang aman dan bersih mampu mendukung minat beli baik dari konsumen maupun calon konsumen.

Temuan ini didukung hasil penelitian Baskaran et al. (2017) bahwa unsur kemasan sangat penting dalam mendukung pilihan dan perilaku pembelian konsumen dengan mengalihkan pikiran mereka melalui kemasan yang dirasakan. Aspek ini bisa memiliki pengaruh signifikan terhadap niat pembelian pelanggan, sebab pelanggan dipengaruhi oleh aspek penampilan produk (kemasan) dalam perilaku pembelian yang tidak direncanakan (Mirabi et al., 2015).

Kedua, perceived value memiliki ratarata jawaban responden tertinggi pada item pernyataan ketiga. Temuan ini menunjukkan bahwa konsumen atau calon konsumen setuju secara keseluruhan, produk Tenun Kubang $\mathrm{H}$. Ridwan BY sangat bernilai tinggi. Temuan tersebut disebabkan karena manfaat dari produk tenun sebanding dengan jumlah uang yang dibayarkan. Adapun jenis produk tenun Kubang H. Ridwan BY diantaranya adalah kain tenun, kain songket, baju kemeja tenun, baju kebaya tenun kombinasi bordir, baju kebaya tenun kombinasi sulaman, aksesoris, dan lain-lain. Selain itu, pihak tenun juga memberikan harga yang wajar karena harga ditetapkan sesuai dengan motif dan kualitas tenun.

Berikutnya, rata-rata jawaban tertinggi variabel perceived quality terdapat pada item pernyataan keempat, yaitu merek Tenun Kubang H. Ridwan BY mungkin memiliki keunikan dibanding merek pesaing. Salah satu keunikannya yaitu ada dua motif tenun yang telah mendapatkan pengakuan hak kekayaan intelektual (HKI) dari Kementerian Hukum dan Hak Asasi Manusia Republik Indonesia. Motif yang telah mendapatkan sertifikat HKI adalah motif kelok paku basusun dan motif merak jo kupu-kupu. Pengakuan HKI ini bisa meyakinkan baik konsumen maupun calon konsumen bahwa Tenun Kubang H. Ridwan BY mempunyai produk berkualitas melalui motif unik dan tidak bisa ditiru oleh pesaing, sehingga meningkatkan minat beli. Hal serupa juga telah diteliti oleh Kar et al. (2018) bahwa persepsi kualitas adalah faktor terpenting dalam memprediksi niat beli konsumen terhadap produk makanan. 
Sebelum melakukan pembelian sebuah produk, konsumen mempunyai beberapa persepsi tentang kualitas, produk, dan harga (Saleem et al., 2015). Setelah menggunakan produk, niat beli konsumen bisa meningkat atau menurun. Jika produk berkualitas tinggi, maka niat beli juga akan bertambah tinggi (Konuk, 2018). Persepsi kualitas dianggap konsumen sebagai fitur produk dan layanan (Saleem et al., 2015). Perusahaan mempunyai kendali atas kualitas produk, karena kualitas produk dapat menentukan niat beli konsumen (Beneke et al., 2015).

Keempat, nilai rata-rata tertinggi pada variabel purchase intention terdapat pada item pernyataan kedua, yaitu mungkin responden akan membeli produk Tenun Kubang $\mathrm{H}$. Ridwan BY. Hasil penelitian ini mengindikasikan bahwa minat konsumen membeli tenun Kubang H. Ridwan BY cukup tinggi.

Adanya manfaat yang dirasakan dari produk tenun, baik dari kemasan maupun kualitasnya, menyebabkan konsumen dan calon konsumen bersedia membeli produk tenun untuk tujuan memenuhi kebutuhannya. Evaluasi produk oleh konsumen setelah digunakan disebut sebagai niat beli (Saleem et al., 2015). Selain itu, anggapan manfaat dan kualitas juga mendorong sikap konsumen atau calon konsumen untuk merekomendasikan produk Tenun Kubang H. Ridwan BY kepada temannya. Keseluruhan temuan ini mampu mendorong peningkatan minat beli konsumen atas produk-produk tenun yang ditawarkan.

\section{SIMPULAN}

Dari keseluruhan hasil temuan, bisa disimpulkan bahwa pihak Tenun Kubang $\mathrm{H}$. Ridwan BY harus meningkatkan perceived packaging, perceived value, dan perceived quality. Hal ini bertujuan agar purchase intention konsumen dan calon konsumen bisa meningkat. Dilihat dari nilai setiap indikator, semakin tinggi nilai rata-rata maka implikasi dari setiap variabel juga sudah lebih baik. Sebaliknya, jika nilai rata-rata dari indikator semakin rendah maka hal ini bisa menjadi bahan rekomendasi untuk upaya perbaikan dan peningkatan bagi usaha Tenun Kubang $\mathrm{H}$. Ridwan BY.

Temuan-temuan tersebut menunjukkan bahwa perceived packaging, perceived value, dan perceived quality tenun Kubang $\mathrm{H}$. Ridwan dinilai baik oleh pihak konsumen, sedangkan minat konsumen maupun calon konsumen menjadi cukup tinggi terhadap produk tenun Kubang H. Ridwan BY. Namun demikian, perlu beberapa peningkatan sebagai bahan rekomendasi untuk kemajuan usaha. Pertama, pihak usaha harus lebih meyakinkan konsumen bahwa kemasan dari produk yang mereka miliki adalah lebih mudah dibuka jika dibandingkan dengan milik pesaing. Meski demikian, kemasan tetap aman untuk menyimpan produk tenun.

Kedua, pihak usaha tenun Kubang perlu mempertimbangkan untuk membuat produk dengan harga yang lebih terjangkau bagi masyarakat ekonomi ke bawah. Meski dinilai menawarkan harga yang wajar sesuai kualitas, namun dinilai perlu untuk menambah pangsa pasar. Upaya ini perlu dilakukan agar seluruh kalangan masyarakat bisa membeli produk tenun Kubang H. Ridwan BY.

Ketiga, pihak usaha Tenun Kubang juga harus mampu lebih meyakinkan konsumen maupun calon konsumen bahwa produkproduk mereka adalah sangat berkualitas. Hal ini bisa dilakukan melalui peningkatan upaya promosi di media sosial, seperti facebook, website maupun instagram. Dengan memperhatikan ketiga faktor itu, maka pihak usaha tenun Kubang H. Ridwan BY secara langsung juga perlu mempertimbangkan hal-hal yang menjadi elemen strategi pemasaran yang dipandang akan mendorong niat beli dari konsumen maupun calon konsumen. 


\section{UCAPAN TERIMA KASIH}

Penulis menyatakan terima kasih kepada Kementerian Riset Tekonologi dan Pendidikan Tinggi Republik Indonesia atas bantuan finansial untuk penelitian ini melalui skim Penelitian Terapan Nomor: T/36/UN.16.17/ PT.01.03/PT-SosialHumaniora/2020 Tanggal: 10 Maret 2020.

\section{REFERENSI}

Ansari, A., \& Riasi, A. (2016). An investigation of factors affecting brand advertising success and effectiveness. International Business Research, 9(4), 20-30. doi: 10.5539/ibr.v9n4p20.

Asshidin, N. H. N., Abidin, N., \& Borhan, H. B. (2016). Perceived quality and emotional value that influence consumer's purchase intention towards American and local products. Procedia Economics and Finance, 35, 639-643. doi: 10.1016/S2212-5671(16)00078-2.

Barus, A. C., Panggabean, R., Sinaga, A., Manik, Y., Setiyadi, Y., Simanjuntak, M., \& Situmeang, R. (2015). Piranti Cerdas Penghasil Motif Tenun Nusantara. Institut Teknologi Del and Institut Teknologi Bandung.

Baskaran, S., Ayob, S. A., Howe, N. C., \& Mahadi, N. (2017). Understanding purchase intention of ready-to-eat food among Malaysian urbanites: A proposed framework. International Journal of Academic Research in Business and Social Sciences, 7(11), 566-579. doi: 10.6007/IJARBSS/v7-i11/3496.

Beneke, J., Brito, A., \& Garvey, K-A. (2015). Propensity to buy private label merchandise: The contributory effects of store image, price, risk, quality and value in the cognitive stream. International Journal of Retail \& Distribution Management, 43(1), 43-62. doi: 10.1108/IJRDM-09-2013-0175.

Beneke, J., Flynn, R., Greig, T., \& Mukaiwa, M. (2013). The influence of perceived product quality, relative price and risk on customer value and willingness to buy: A study of private label merchandise. Journal of Product \& Brand Management, 22(3), 218-228. doi: 10.1108/JPBM-02-2013-0262.

Brommer, E., Stratmann, B., \& Quack, D. (2011). Environmental impacts of different methods of coffee preparation. International Journal of Consumer Studies, 35(2), 212-220. doi: 10.1111/ j.1470-6431.2010.00971.x.

Lal, R. C., Yambrach, F., \& McProud, L. (2015). Consumer perceptions towards package designs: A cross cultural study. Journal of Applied Packaging Research, 7(2), 61-94. doi: 10.14448/japr.04.0004.

Chen, W. (2013). Perceived value in community supported agriculture (CSA): A preliminary conceptualization, measurement, and nomological validity. British Food Journal, 115(10), 1428-1453. doi: 10.1108/BFJ-01-20110013.

Erdoğmuş, İ., \& Büdeyri-Turan, I. (2012). The role of personality congruence, perceived quality and prestige on readyto-wear brand loyalty. Journal of Fashion Marketing and Management, 16(4), 399-417. doi: 10.1108/13612021 211265818.

Gendel-Guterman, H., \& Levy, S. (2013). Does consumers' personal involvement have an influence on store brand buying proneness? Journal of Consumer Marketing, 30(7), 553-562. doi: 10. 1108/JCM-06-2013-0582.

Ha, J., \& Jang, SC. (S). (2010). Perceived values, satisfaction, and behavioral intentions: The role of familiarity in Korean restaurants. International Journal of Hospitality Management, 29(1), 2-13. doi: 10.1016/j.ijhm.2009. 03.009 .

Hair, J. F., Ringle, C. M., \& Sarstedt, M. (2011). PLS-SEM: Indeed a silver bullet. Journal of Marketing Theory and Practice, 19(2), 139-152. doi: 10.2753/ MTP1069-6679190202. 
Hellström, D., \& Nilsson, F. (2011). Logistics-driven packaging innovation: A case study at IKEA. International Journal of Retail \& Distribution Management, 39(9), 638-657. doi: 10. 1108/09590551111159323.

Tsiotsou, R. (2006). The role of perceived product quality and overall satisfaction on purchase intentions. International Journal of Consumer Studies, 30(2), 207-217. doi: 10.1111/j.1470-6431. 2005.00477.x.

Ilicic, J., \& Webster, C. M. (2011). Effects of multiple endorsements and consumercelebrity attachment on attitude and purchase intention. Australasian Marketing Journal (AMJ), 19(4), 230237. doi: 10.1016/j.ausmj.2011.07.005.

Jalilvand, M. R., Samiei, N., \& Mahdavinia, S. H. (2011). The effect of brand equity components on purchase intention: An application of Aaker's model in the automobile industry. International Business and Management, 2(2), 149158. Retrieved from http://www. cscanada.net/index.php/ibm/article/view /j.ibm.1923842820110202.016.

Kar, P., Meena, H. R., \& Patnaik, N. M. (2018). Factors influencing consumers purchase intention towards organic and cloned animal food products. International Journal of Current Microbiology and Applied Sciences, 7(1), 1-9. doi: 10.20546/ijcmas.2018. 701.001 .

Khattak, M. N., \& Shah, T. A. (2011). Consumers' attitudes towards non-local products: A case of Pakistan. In 2nd International Conference on Business and Economic Research (2nd Icber 2011) Proceeding, 321-332. Retrieved from http://www.internationalconference.com.my/proceeding/2ndicber2011_pr oceeding/122-2nd\%20ICBER\%202011 $\% 20 \mathrm{PG} \% 20321-332 \% 20$ Consumers $\%$ 20Attitudes.pdf.

Kim, S-B., Sun, K-A., \& Kim, D-Y. (2013). The influence of consumer value-based factors on attitude-behavioral intention in social commerce: The differences between high-and low-technology experience groups. Journal of Travel \& Tourism Marketing, 30(1-2), 108-25. doi: 10.1080/10548408.2013.751249.

Konuk, F. A. (2018). The role of store image, perceived quality, trust and perceived value in predicting consumers' purchase intentions towards organic private label food. Journal of Retailing and Consumer Services, 43(July), 304-310. doi: 10.1016/j.jretconser.2018.04.011.

Lee, S., Sung, B., Phau, I., \& Lim, A. (2019). Communicating authenticity in packaging of Korean cosmetics. Journal of Retailing and Consumer Services, 48(May), 202-214. doi: 10.1016/j. jretconser.2019.02.011.

Li, J., Li, J., \& Zheng, Y. (2013). Corporate image cognition influence perceived quality and purchase intention empirical research. iBusiness, 5(3), 162-167. doi: 10.4236/ib.2013.53B035.

Lita, R. P., Faisal, R. F., Gusmai, M., Rahmi, D. Y., \& Meuthia. (2019). Model keterkaitan inovasi produk, citra merek, persepsi nilai dan intensi pembelian produk kerajinan tenun kubang di Sumatera Barat. Jurnal Manajemen \& Kewirausahaan, 7(2), 100-111. doi: 10.26905/jmdk.v7i2.3290.

Lita, R. P., Meuthia \& Faisal, R. F. (2018). SME's performance of creative industries supporting tourism in Indonesia: Market orientation, learning orientation and organizational innovativeness as determinants. Academy of Marketing Studies Journal, 22(1), 1-18. Retrieved from https://www.abacademies.org/journals/.

Lomboan, L. K. (2017). Analysis the influence of perceived quality, perceived price and perceived value on consumer purchase intention in traditional fabrics (Case study Kaeng Manado). Jurnal Berkala Ilmiah Efisiensi, 17(1), 100-112. Retrieved from https://ejournal.unsrat.ac.id/index. php/jbie/article/view/14907. 
Meirejeki, I. N., Pemayun, I. D. G. A., \& Sudarmini, N. M. (2017). Pemilihan industri unggulan sebagai dasar pengembangan industri kerajinan di Kabupaten Jembrana. Jurnal Bisnis dan Kewirausahaan, 12(1), 74-82. Retrieved from http://ojs.pnb.ac.id/index.php/JBK/ article/view/35.

Mirabi, V., Akbariyeh, H., \& Tahmasebifard, H. (2015). A study of factors affecting on customers purchase intention case study: The agencies of Bono brand tile in Tehran. Journal of Multidisciplinary Engineering Science and Technology (JMEST), 2(1), 267-273. Retrieved from https://pdfs.semanticscholar.org/4518/6 76346f0734f26d3915cd612f0e44f889df 5.pdf.

Mulki, J. P., \& Jaramillo, F. (2011). Ethical reputation and value received: Customer perceptions. International Journal of Bank Marketing, 29(5), 358-372. doi: $10.1108 / 02652321111152891$.

Musharraf, M. B., \& Ali, T. (2013). Factors influencing consumers purchase intentions towards private brands. Journal of Independent Studies and Research-Management, Social Sciences and Economics, 11(2), 17-28. Retrieved from https://papers.ssrn.com/sol3/ papers.cfm?abstract_id=2536282.

Nilforushan, S., \& Haeri, F. A. (2015). The effect of packaging design on customers' perception of food products' quality, value, and brand preference (Case study: Pegah pasteurized cheese, in Isfahan City). WALIA Journal, 31(S3), 127-132. Retrieved from https:// www.semanticscholar.org/paper/Theeffect-of-packaging-design-on-customers-\%E2\%80\%99-of-\%E2\%80\%99Nilforushan-Haeri/b5e9fe3de30eb95 ba1cb131fdfd9ab6d5a895e96.

Quintal, V., Phau, I., Sims, D., \& Cheah, I. (2016). Factors influencing generation Y's purchase intentions of prototypical versus Me-Too brands. Journal of Retailing and Consumer Services, 30(May), 175-183. doi: 10.1016/j. jretconser.2016.01.019.
Saeed, A.F-u-H., Khan, S. N., Sarwar, A., \& Tahira, J. J. (2010). Effect of packing materials on storage of tomato. Mycopath, 8(2), 85-89. Retrieved from https://www.researchgate.net/publicatio n/274254294_Effect_of_packing_materi als_on_storage_of_tomato.

Saeed, F., \& Grunert, K. G. (2014). Expected and experienced quality as predictors of intention to purchase four new processed beef products. British Food Journal, 116(3), 451-471. doi: 10.1108/ BFJ-10-2011-0262.

Saleem, A., Ghafar, A., Ibrahim, M., Yousuf, M., \& Ahmed, N. (2015). Product perceived quality and purchase intention with consumer satisfaction. Global Journal of Management and Business Research, 15(1), 21-27. Retrieved from https://globaljournals.org/GJMBR_Volu me15/3-Product-Perceived-Quality.pdf.

Sekaran, U., \& Bougie, R. (2016). Business research methods: A skill-building approach $\left(7^{\text {th }}\right.$ ed.). John Wiley \& Sons.

Setiawan, B., \& Suwarningdyah, R. R. N. (2014). Strategi pengembangan tenun ikat kupang Provinsi Nusa Tenggara Timur. Jurnal Pendidikan dan Kebudayaan, 20(3), 353-367. doi: 10.24832/jpnk.v20i3.150.

Shafiq, R., Raza, I., \& Zia-ur-Rehman, M. (2011). Analysis of the factors affecting customers' purchase intention: The mediating role of perceived value. African Journal of Business Management, 5(26), 8041-8049. doi: 10.5897/ AJBM10.1088.

Trisnayana, I. K., Suartini, L., \& Budiarta, I. G. M. (2016). Proses pembuatan tenun Flores home industri Ibu Yustina Nona di Desa Tanjung Benoa. Jurnal Pendidikan Seni Rupa Undiksha, 6(3), 1-11. doi: 10.23887/jjpsp.v6i3.7181.

Utami, H. N., Sadeli, A. H., \& Perdana, T. (2016). Customer value creation of fresh tomatoes through branding and packaging as customer perceived quality. International Society for Southeast Asian Agricultural Sciences- 
Philippines, 22(1), 123-36. Retrieved from https://www.researchgate.net/ publication/306209540_Customer_valu e_creation_of_fresh_tomatoes_through_ branding_and_packaging_as_customer_ perceived_quality.

Venter, K., van der Merwe, D., de Beer, H., Kempen, E., \& Bosman, M. (2011). Consumers' perceptions of food packaging: An exploratory investigation in Potchefstroom, South Africa. International Journal of Consumer Studies, 35(3), 273-281. doi: 10.1111/j.14706431.2010.00936.x.

Wang, E. S. T. (2013). The influence of visual packaging design on perceived food product quality, value, and brand preference. International Journal of Retail \& Distribution Management, 41(10), 805-816. doi: 10.1108/IJRDM12-2012-0113.

Wu, P. C. S., Yeh, G. Y-Y., \& Hsiao, C-R. (2011). The effect of store image and service quality on brand image and purchase intention for private label brands. Australasian Marketing Journal (AMJ), 19(1), 30-39. doi: 10.1016/j. ausmj.2010.11.001.
Younus, S., Rasheed, F., \& Zia, A. (2015). Identifying the factors affecting customer purchase intention. Global Journal of Management and Business Research: A Administration and Management, 15(2), 9-13. Retrieved from https://globaljournals.org/GJMBR_Volu me15/2-Identifying-the-FactorsAffecting.pdf.

Zarantonello, L., \& Schmitt, B. H. (2010). Using the brand experience scale to profile consumers and predict consumer behaviour. Journal of Brand Management, 17(7), 532-540. doi: 10.1057/bm. 2010.4 . 